\title{
Distribution and conservation significance of endemic species of flowering plants in Peru
}

\author{
HENK VAN DER WERFF* and TRISHA CONSIGLIO \\ Center for Conservation and Sustainable Development, Missouri Botanical Garden, P.O. Box 299, St. \\ Louis, MO 63166, USA; *Author for correspondence (e-mail: henk.vanderwerff@mobot.org)
}

Received 2 December 2002; accepted in revised form 17 June 2003

Key words: Elevational zones, Endemics, Flowering plants, Life forms, Peru

Abstract. Using the data published in the Catalogue of the Flowering Plants and Gymnosperms of Peru, we analyzed the elevational distributions of 5323 species reported as endemics from that country as a whole, for 10 families with the highest number of endemic taxa in Peru, and the distribution patterns of these species according to life form. We calculated the density of endemism (number of endemic species divided by area $\times 1000$ ) and absolute number of endemic species among life forms and families, along an elevational gradient. Overall densities of endemics were 10-15 times higher at mid-elevation (2000$3500 \mathrm{~m})$ than in the Amazonian lowlands $(0-500 \mathrm{~m})$. Absolute numbers of endemics peaked at 1500 $3000 \mathrm{~m}$ for herbs, shrubs, and epiphytes, while trees, vines, and lianas showed maxima in the lowlands $(0-500 \mathrm{~m})$; yet densities of endemics for all life forms peaked at $1500-3000 \mathrm{~m}$. Among the 10 families with the highest number of endemics, densities of endemics peaked at mid- to high elevation (1500$4500 \mathrm{~m}$ ), but showed much disparity in the elevational distribution of absolute numbers of endemic species. Finally, the percentage of endemic species to total species is highest for herbs, shrubs, and epiphytes. Given that less than $10 \%$ of the land area for each of the montane zones $(2000-4500 \mathrm{~m})$ is protected compared to $13.5-29.9 \%$ in the lower elevations $(0-1000 \mathrm{~m})$, we recommend that priority be given to increasing the size of protected areas at mid- to high altitude in the Andean slopes to grant further protection in zones with the highest density of endemics. We also recommend that more emphasis be given to collecting and studying non-trees, since most endemic species belong to that class.

\section{Introduction}

The elevational patterns of endemism in the tropics generally show increasing endemism with elevation, peaking at mid- to high elevations and declining above the timberline (Gentry 1986; Balslev 1988; Major 1988; Ibisch et al. 1996; Sklenar and Jørgensen 1999; Kessler 2000, 2001a, b, 2002a, b; Kessler et al. 2001). However, much is still unknown about the elevational gradient of endemism among different biogeographic regions, and about varying degrees of endemism within and between taxonomic plant families in the same biogeographic zone. Factors thought to influence endemism include fragmented habitats and variation in climatic and edaphic conditions within short distances in montane areas, leading to isolation of small species populations subject to differentiation (Kruckeberg and Rabinowitz 1985; Gentry 1986; Major 1988). Few generalizations can be made about endemism, and recent studies have highlighted the role of life form, pollination mode, and ecophysiological type influencing endemism at the community and species level (Kessler 2000, 2002b; Knapp 2002; Luteyn 2002). The degree of endemism 
for an area is often cited as a measure of the uniqueness of the flora and consequently is important for prioritizing sites for conservation (Myers et al. 2000; Brooks et al. 2002; Knapp 2002; Young et al. 2002). The Andes Mountains, in particular, are known to harbor high levels of endemism and are experiencing rapid habitat loss (Gentry 1986, 1995; Mittermeier et al. 1998), resulting in their conservation 'hotspot' status (Myers et al. 2000). We assign great importance to areas of high endemism for conservation strategies; however, it has also been suggested that human curiosity for rare objects may contribute to our preoccupation with endemic organisms (Kruckeberg and Rabinowitz 1985), and endemic plants may actually be competitively inferior to other more widespread taxa (Kessler 2001b). Nonetheless, understanding the evolutionary processes contributing to endemism will be critical in deciding how to direct our conservation energies (Young et al. 2002). Only by conserving areas of high endemism will we be able to further study the ecological, life history, and physiological factors influencing endemics while simultaneously protecting areas of variable habitat.

In this paper we used the Catalogue of the Flowering Plants and Gymnosperms of Peru (Brako and Zarucchi 1993) to analyze the elevational distributions of 5323 species reported as endemics from Peru as a whole, for 10 families with the highest number of endemic taxa in Peru, and the distribution patterns of these endemics according to life form. Including analyses for selected plant families and different life forms is essential for assessing the effect of elevational gradients on endemism for plant taxa within the same biogeographic region and among different life forms. Only one study to date has analyzed the elevational patterns of endemism for an entire flora at both the country and family level (Kessler 2002b), suggesting a need for more research into the role of topography for patterns of endemism for plant taxa within biogeographical regions and for comparative studies of the same plant families in different biogeographical areas. Especially unique to our study are the analyses of the elevational distributions of endemic species across life forms for an entire flora.

The Catalogue of the Flowering Plants and Gymnosperms of Peru (Brako and Zarucchi 1993) listed 17143 taxa from Peru with their geographical and elevational distribution; of those, 5354 were endemic. The current study is based on the 5323 endemic species (intraspecific taxa excluded) that are included in the table made during the writing of the Catalogue that lists all species. The Catalogue presented a wealth of information, but has not been used much other than by taxonomists.

Ibisch et al. (1996) used data from the Catalogue in their analysis of the Peruvian epiphytes, but this study is an exception. The amount of information in the Catalogue is so great that extracting a subset (for instance, all species reported from a particular Department, all tree species, or all species occurring above $3000 \mathrm{~m}$ altitude) is a daunting job. However, such subsets can provide insight into the role of elevational gradients and life form for endemics by addressing questions such as: Are endemic species concentrated in particular elevational zones? Which major life form (herbs, shrubs, trees, epiphytes, vines, lianas) includes the largest number of endemics? Are elevational distributions of endemic species similar among different life forms? Finally, are elevational distributions of endemic species similar within 
selected plant families? In this paper we attempt to answer these questions and explore the consequences that our findings will have for conservation issues and future research.

\section{Materials and methods}

The data from the Catalogue were imported into database spreadsheets and analyzed using the Excel and ArcView programs. Elevational zones for Peru were derived from the GTOPO 30 Digital Elevation Model (U.S. Geological Survey 1996) using ArcView Spatial Analyst. The elevation grid was clipped for Peru and reclassified into 10 zones of $500 \mathrm{~m}$ increments and one zone for all elevations $>5000 \mathrm{~m}$. The Peru Catalogue lists endemics occurring up to $5000 \mathrm{~m}$; the total area above this elevation accounts for only $0.06 \%$ of the total area of Peru. The area in square kilometers was then calculated for each elevational zone (Zhou 2001). A Department data layer was added (ESRI 1999) and area was calculated in square kilometers for each Department. Area data were used throughout the study to analyze the density of endemics along elevational zones and between life forms. Area calculations for protected areas were based on the Mapa de Areas Naturales Protegidas Del Peru, which can be seen on the INRENA web site (http://www. inrena.gob.pe/dganp.html). Using ArcView Spatial Analyst, we digitized the map onto our DEM layer of Peru and calculated the area of each elevational zone within the parks, as well as the total area for all parks; our figure $(17,178,174 \mathrm{ha})$ differed by only $0.6 \%$ from the total for the protected areas given by INRENA $(17,360,009$ ha less 64,115 ha for the Cordillera de Colan, which is not on the map). We thus accepted that our calculations were largely correct. Table 5 presents the elevational distribution of the protected areas.

The data used in this contribution are taken from the Catalogue (Brako and Zarucchi 1993); by implication, new species and new records for the flora of Peru during the last 10 years are not included in our numbers. Despite these and other limitations described below, we believe that the data are sufficient for the kind of analysis presented in this paper. Data from the Catalogue of the Vascular Plants of Ecuador (Jørgensen and León-Yánez 1999) provide a useful perspective on the most species-rich families and the completeness of the data in the Peru Catalogue. Although smaller than Peru, Ecuador is comparable to Peru in the variety of its habitats, which range from semi-deserts, rainforest, and montane forest to páramo, and it is reasonable to expect that the floras of the two countries are similar. In Table 1 we list the 10 families in Peru with the largest numbers of species in descending order, their species numbers, and the corresponding species numbers from the Catalogue of Ecuador. A quick glance shows that essentially the same 10 families occupy the top 10 positions in both countries, with some changes in the rankings. The two largest families are the same in both countries.

It is difficult to answer the question of how complete the species numbers included in the Catalogues of Peru and Ecuador really are. We cannot state how many species in Peru and Ecuador remain undescribed. We can, however, determine how 


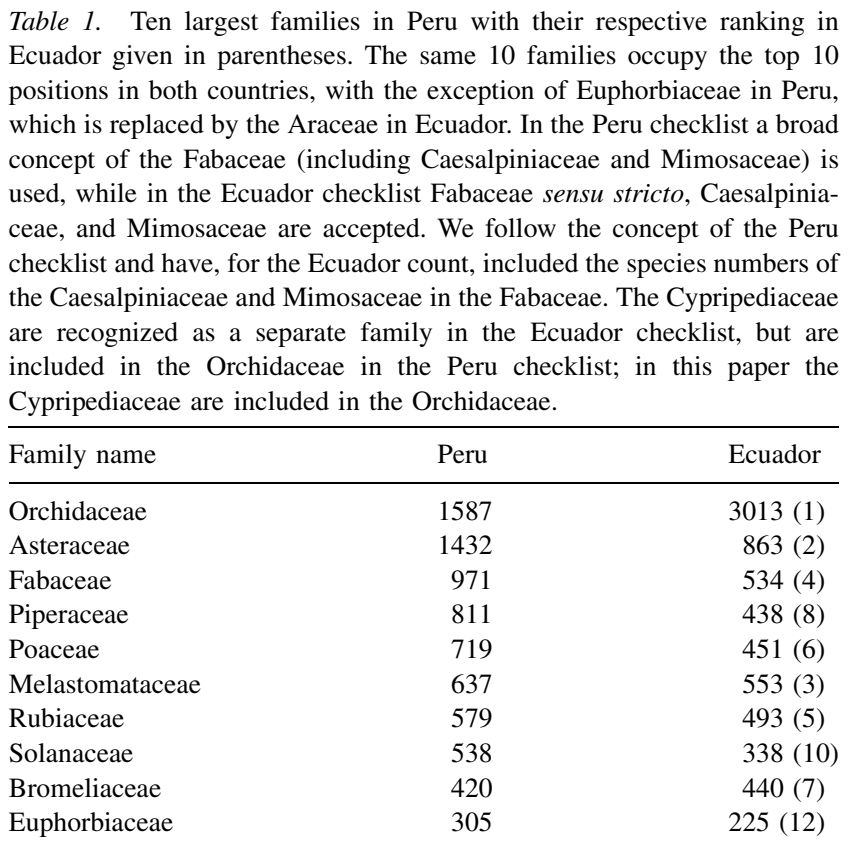

many species have been described from Peru or Ecuador during the last decades. Our data for Ecuador are the most complete: about 160 species have been described every year since 1973 based on type specimens collected in Ecuador (D. Neill, personal communication). There are no signs that this number, about 4800 species described from Ecuador since 1973, is declining; the main limit on the number of species described is the lack of botanists studying the plants. The number of new records for Ecuador is lower, with about 50 species annually during the last 3 years (D. Neill, personal communication). The largest plant family in Peru and Ecuador are the Orchidaceae. They show a striking increase in the number of known species from Ecuador due to the efforts of a team of specialists stimulated by Calaway Dodson, who is currently writing a treatment of the orchids for the Flora of Ecuador. In the Ecuador Catalogue, published four years ago, 3013 species of orchids were listed. Dodson (personal communication) has now documented 3769 species of orchids from Ecuador, an increase of $25 \%$ in the last 4 years. The Peru Catalogue includes 1587 species of orchids; Dodson now estimates that number to be around 2300, an increase of almost 50\%. Anecdotal evidence of other families (Araceae) supports the notion that the actual numbers of species in Peru and Ecuador may well be $25 \%$ higher than the numbers given in the Catalogues. Obviously, some caution will be necessary when using the data from the Catalogues. In spite of these limitations, we feel that the data are sufficient for the kind of analysis presented in this paper and that an increase in species numbers is not likely to drastically change our conclusions based on the present data set. 
Table 2. Number of endemic species in each Department, the area of each Department, and the density of endemism (number of endemic species in a Department divided by area $\times 1000$ ).

\begin{tabular}{|c|c|c|c|}
\hline Department name & No. endemics & Area $\left(\mathrm{km}^{2}\right)$ & Endemics $/ 1000 \mathrm{~km}^{2}$ \\
\hline Huanuco & 1011 & 36559 & 27.7 \\
\hline Cajamarca & 743 & 34257 & 21.7 \\
\hline Junin & 888 & 44279 & 20.1 \\
\hline Amazonas & 690 & 40816 & 16.9 \\
\hline La Libertad & 379 & 24748 & 15.3 \\
\hline Lima & 450 & 35409 & 12.7 \\
\hline Pasco & 304 & 23943 & 12.7 \\
\hline Ancash & 424 & 36201 & 11.7 \\
\hline San Martin & 553 & 52912 & 10.5 \\
\hline Cusco & 767 & 74528 & 10.3 \\
\hline Huancavelica & 202 & 22208 & 9.1 \\
\hline Apurimac & 166 & 20888 & 7.9 \\
\hline Lambayeque & 89 & 13703 & 6.5 \\
\hline Ayacucho & 284 & 44333 & 6.4 \\
\hline Tumbes & 26 & 4595 & 5.7 \\
\hline Piura & 185 & 36782 & 5.0 \\
\hline Moquegua & 57 & 15221 & 3.7 \\
\hline Arequipa & 232 & 63149 & 3.7 \\
\hline Puno & 265 & 72487 & 3.7 \\
\hline Tacna & 52 & 16108 & 3.2 \\
\hline Loreto & 713 & 374429 & 1.9 \\
\hline Ica & 39 & 21090 & 1.8 \\
\hline Madre de Dios & 112 & 83707 & 1.3 \\
\hline Ucayali & 77 & 104383 & 0.7 \\
\hline Callao & 0 & 178 & 0.0 \\
\hline All of Peru & 5323 & 1296912 & 4.1 \\
\hline
\end{tabular}

\section{Results}

For conservation strategies, species with a limited distribution are of greater importance than species with a wide distribution. We have in this study focused on endemic species and consider them representative for species with a limited distribution. Of course, some of the endemic species may have a relatively wide distribution in Peru, but a sizeable number (3411 out of 5323) are known from only one Department. The number of endemic species varies greatly among Departments (from 0 in Callao to 1011 in Huanuco), as does the area of Departments (from $178 \mathrm{~km}^{2}$ in Callao to $374429 \mathrm{~km}^{2}$ in Loreto), yet correlation of area to number of endemics by Department was not significant $(R=0.31)$. We exclude Callao, the smallest Department, which consists largely of the harbor of Callao, and which has no reported endemics, from further consideration (Table 2). Our data show that the density of endemism (number of endemic species per $1000 \mathrm{~km}^{2}$ ) is 10-15 times higher in the Andean Departments of Amazonas, Cajamarca, Huanuco, and Junin than in the lowland, Amazonian Departments of Loreto, Madre de 
(A)

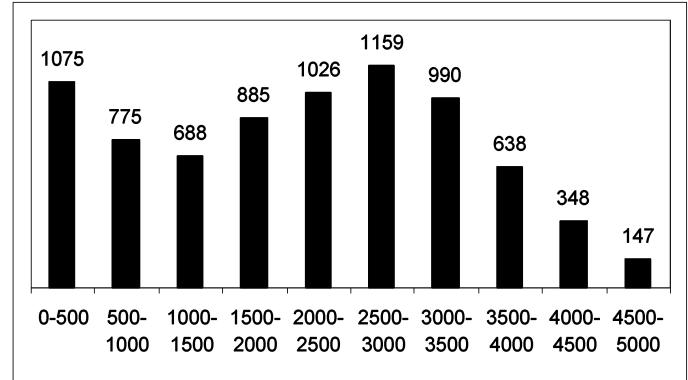

(B)

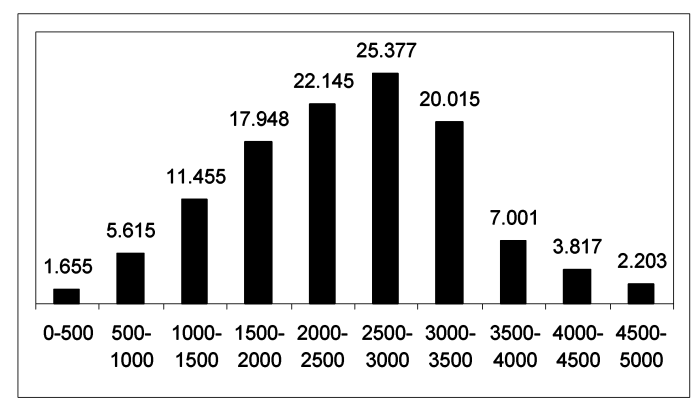

Figure 1. Elevational distribution of endemic species in Peru expressed as (A) absolute numbers of endemic species in each elevational zone (500 m increments), and (B) density of endemics (number of species per $1000 \mathrm{~km}^{2}$ land area for each elevational zone).

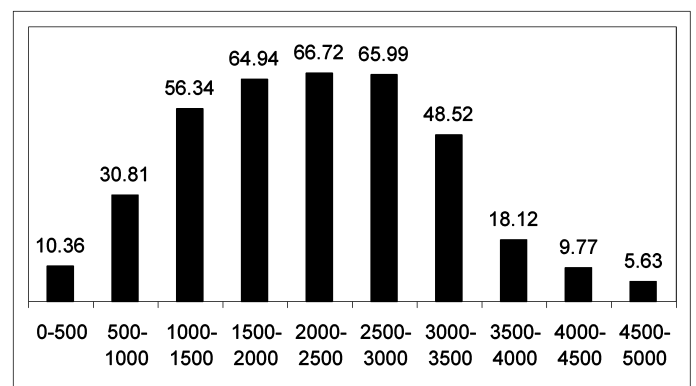

Figure 2. Elevational distribution of density of all flowering species in Peru expressed as the number of species per $1000 \mathrm{~km}^{2}$ land area for each elevational zone.

Dios, and Ucayali. Ucayali has a very low rate of endemism; but this Department was created recently (in the 1980s), and endemics reported before that date from the area are included in numbers for Loreto. A low density of endemism of tree species in the Amazonian lowlands was earlier reported by Pitman et al. (1999), a 


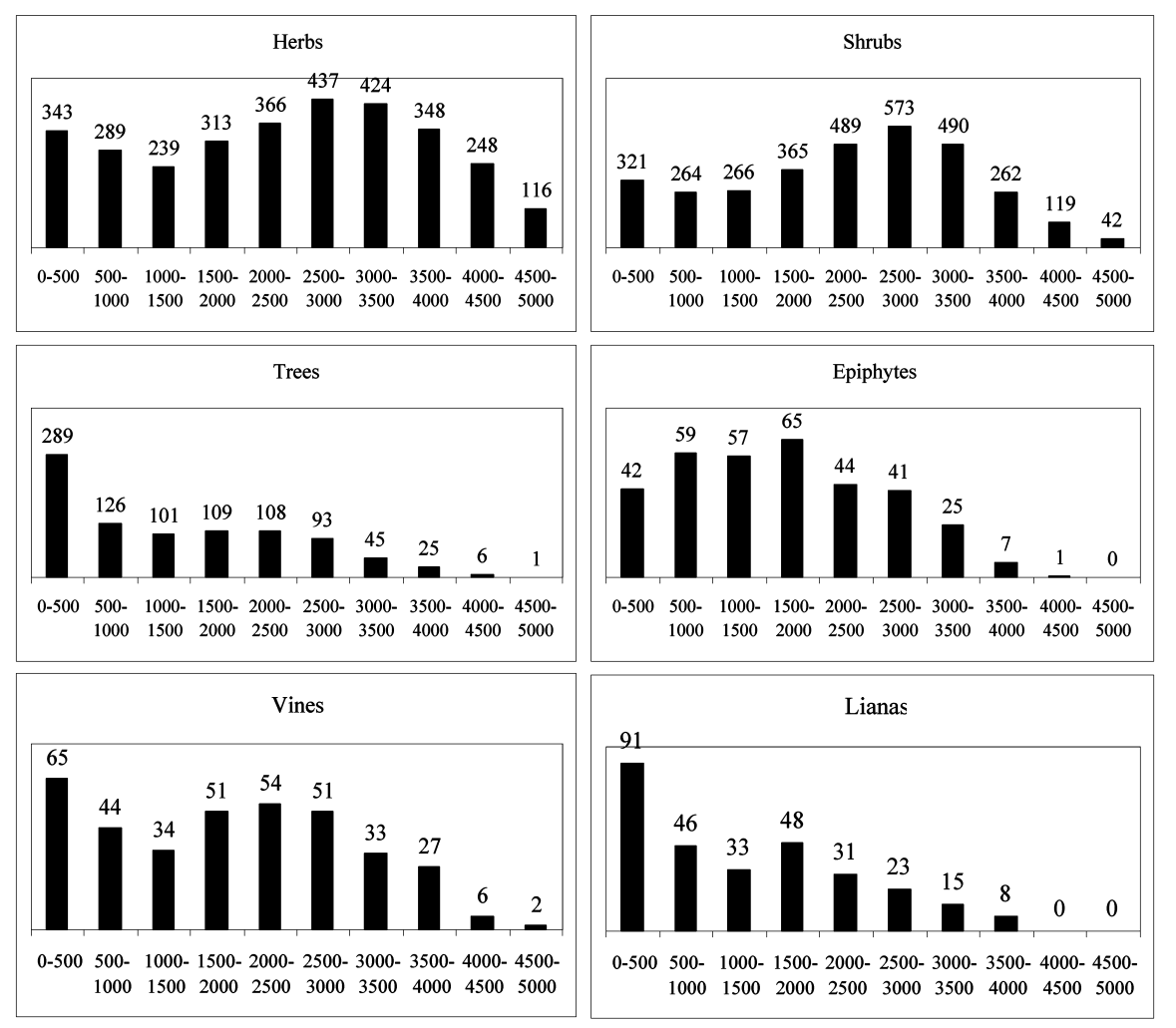

Figure 3. Elevational distribution of life forms for endemic species (absolute numbers). Scandent shrubs, which are included as a separate category of life form in the Catalogue, are counted as shrubs.

conclusion supported by our data on all species. Similarly, analyses of the endemics from Ecuador showed high levels of endemism clearly associated with either the Andes or the Galápagos, but much lower levels of endemism associated with the lowlands of the Coastal and Amazonian regions (Jørgensen and León-Yánez 1999; Valencia et al. 2000). Also included in Table 2 are data for the whole country of Peru. Although the number of endemics in the country is much higher than that in any of the Departments, the density of endemism for the country is relatively low at 4.1; for example, the density of endemics in Huanuco is almost seven times higher than that in the country as a whole. The density of endemics in the Amazonian Departments of Loreto, Madre de Dios, and Ucayali is clearly lower than the national density (4.1 versus $1.9,1.3$, or 0.7$)$.

Especially unique to our study are the analyses of the elevational distribution of endemic species across life forms for Peru. This distribution of endemic species, using absolute numbers, showed two peaks, one at $0-500 \mathrm{~m}$ and another at 2500 $3000 \mathrm{~m}$ (Figure 1). However, density of endemics (number of endemic species per $1000 \mathrm{~km}^{2}$ land area) increased with elevation, peaked at $2500-3000 \mathrm{~m}$, and abruptly 

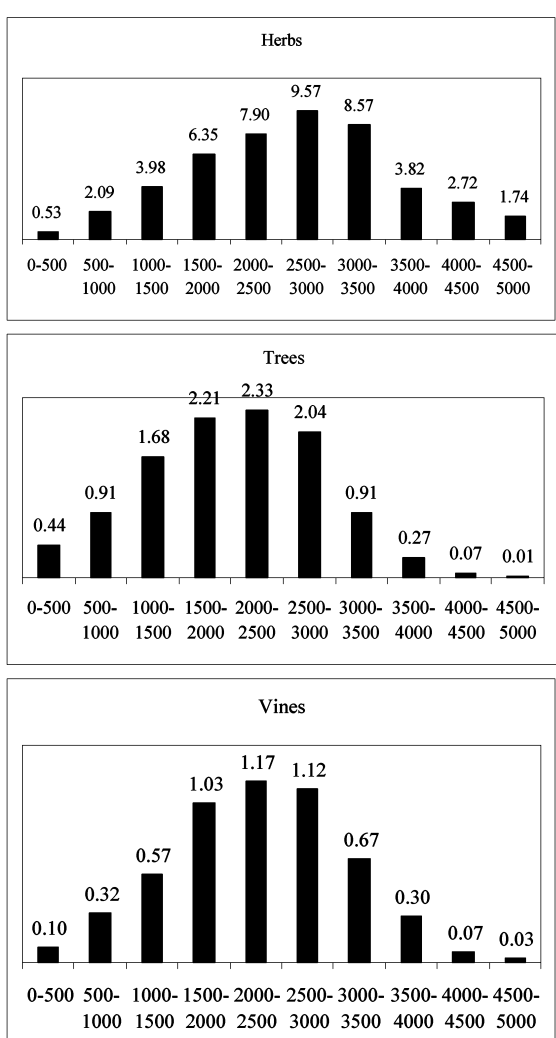
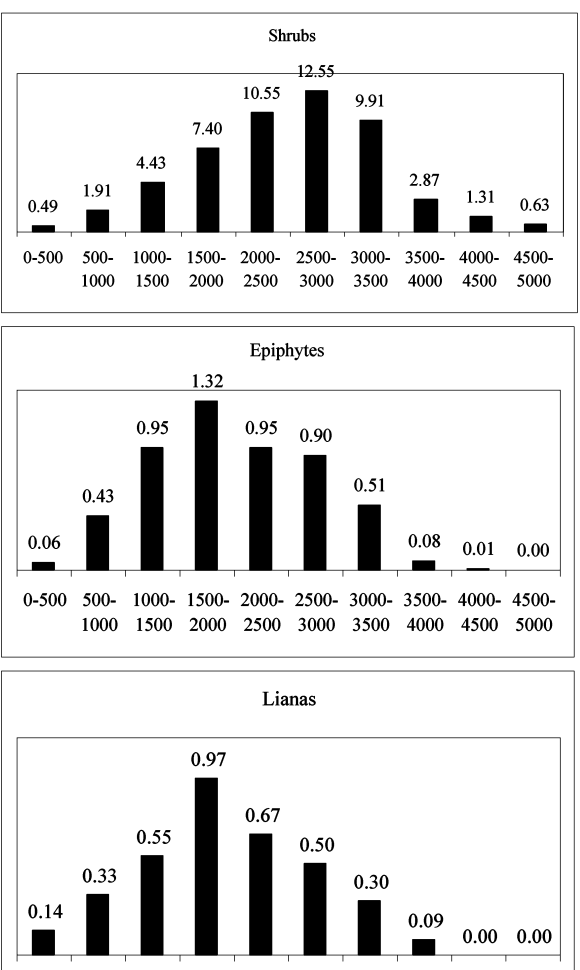

0-500 500- 1000- 1500- 2000- 2500- 3000- 3500- 4000- 4500$\begin{array}{lllllllll}1000 & 1500 & 2000 & 2500 & 3000 & 3500 & 4000 & 4500 & 5000\end{array}$

Figure 4. Elevational distribution of endemic species by life form expressed as density of endemic species. Density was calculated as the number of endemic species per $1000 \mathrm{~km}^{2}$ land area for each elevational zone (500 $\mathrm{m}$ increments).

fell off at elevations over $3500 \mathrm{~m}$ (Figure 1). Density patterns of endemism with elevation were highly correlated $(R=0.92)$ to the density pattern for all species, with both displaying bell-shaped curves (Figure 2). Absolute numbers of endemics peaked at 1500-3000 $\mathrm{m}$ for herbs, shrubs, and epiphytes, while trees, vines, and lianas showed maxima in the lowlands (Figure 3); yet density of endemics peaked at $1500-3000 \mathrm{~m}$ for all life forms (Figure 4).

The percentage of endemic species shows considerable variation between the different life forms. This percentage is highest among the herbs (36.5\%) and shrubs (39.24\%), with epiphytes $(27.35 \%)$ occupying a middle position. The lowest percentages were found among trees $(20.13 \%)$, vines $(21.68 \%)$, and lianas $(18.12 \%)$ (Table 4). In general, the life forms with the most species also had the highest percentages of endemics.

Looking at the altitudinal distribution of the endemic species for the 10 families with the largest numbers of endemic species, we find again a great deal of variation. 


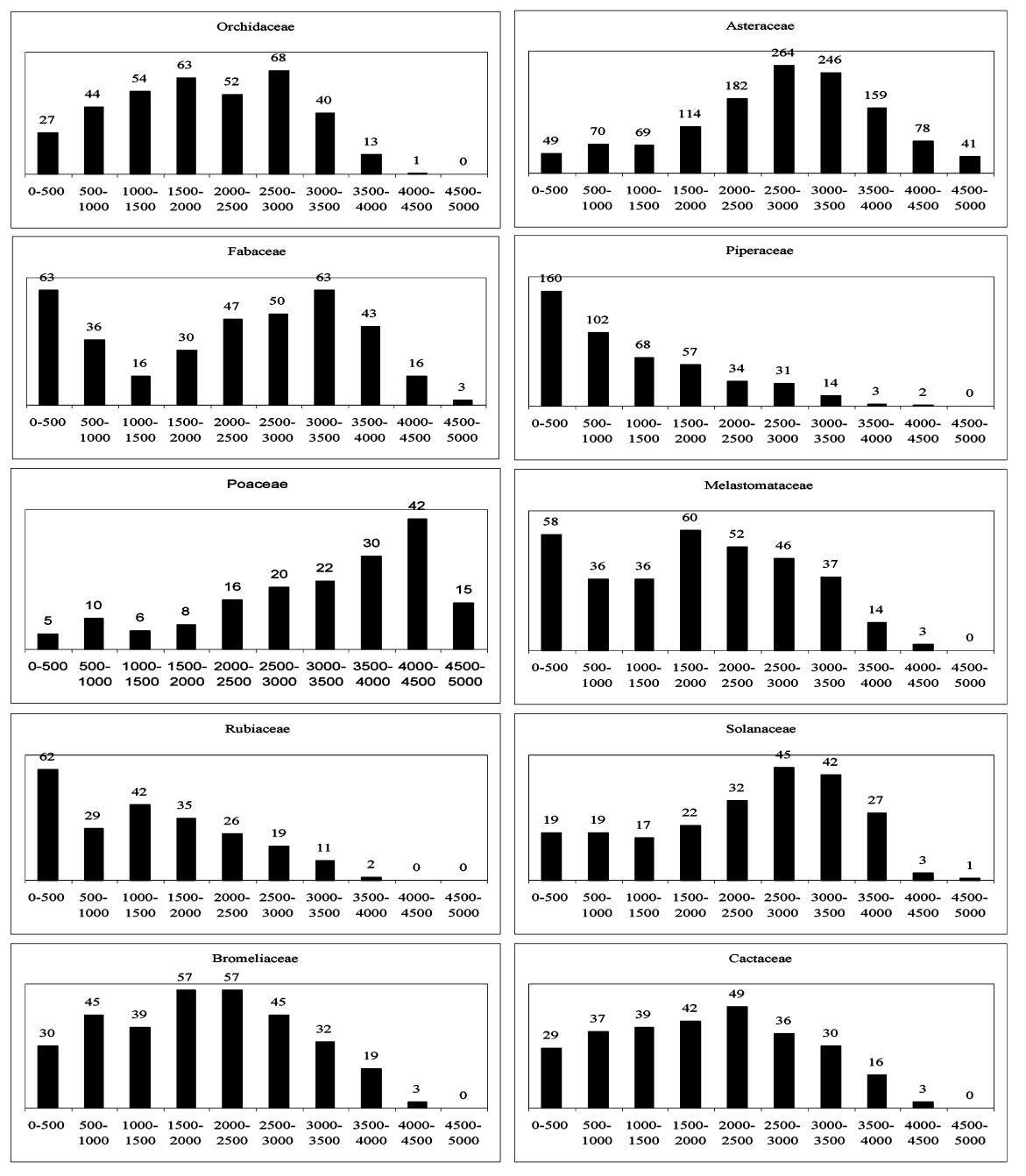

Figure 5. Elevational distribution of endemic species (absolute numbers) for 10 families with the largest number of endemics in Peru.

This variation is most obvious when plotting the absolute number of endemic species for each altitudinal zone (Figure 5). For instance, the figures for Piperaceae and Poaceae are almost exact opposites. Piperaceae show a peak in the lowlands and a gradual decline in number of endemics with increasing altitude, while Poaceae show a peak at high altitude $(4000-4500 \mathrm{~m})$ and a gradual decline with decreasing altitude. Rubiaceae display a similar pattern as the Piperaceae; most other families have an optimum between 1500 and $3500 \mathrm{~m}$, but Fabaceae are the exception with two peaks, one in the lowlands and one at $3000 \mathrm{~m}$. When plotting the 


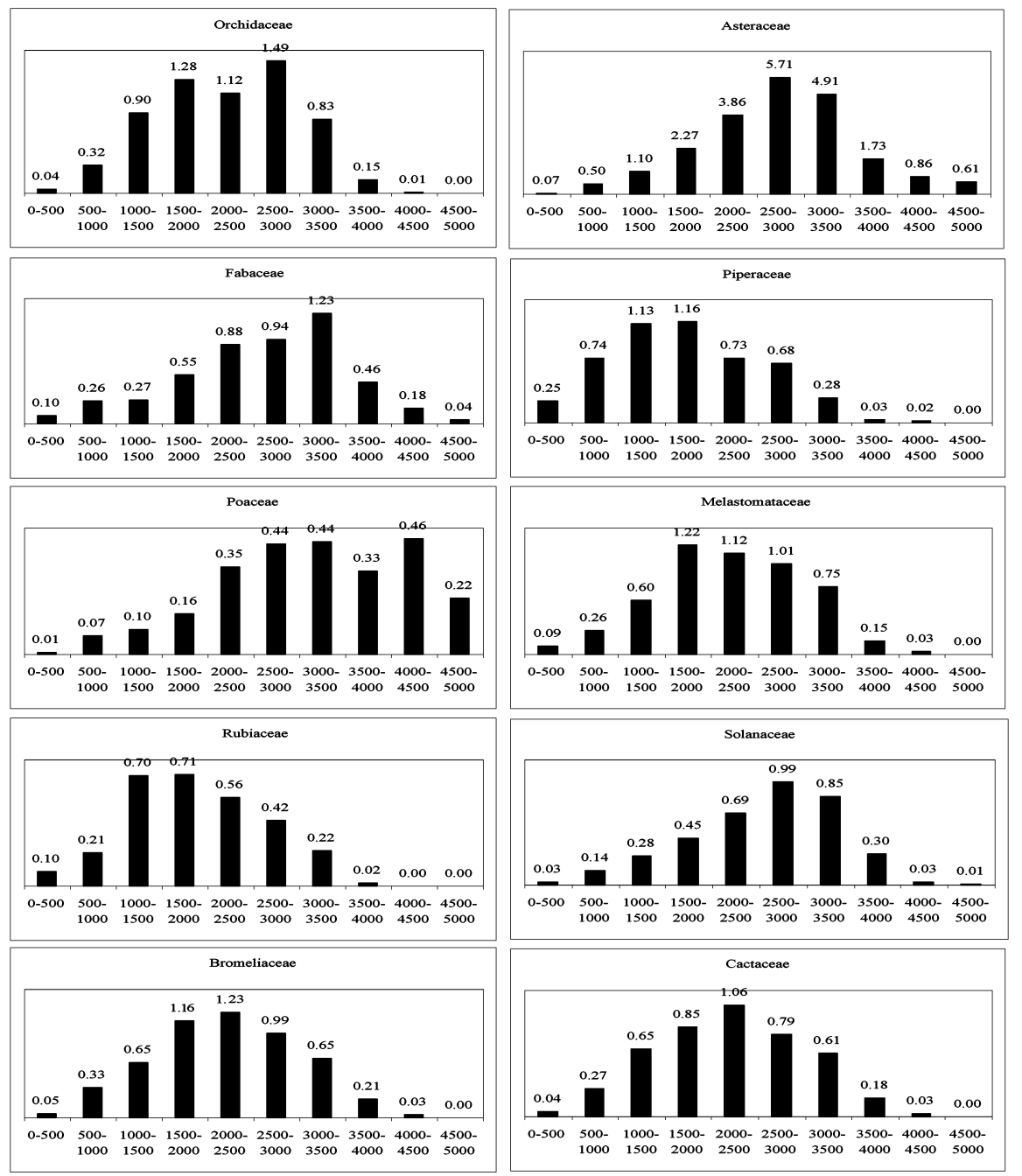

Figure 6. Elevational distribution of the 10 families with the largest number of endemics in Peru expressed as density of endemic species. Density was calculated as the number of endemic species per $1000 \mathrm{~km}^{2}$ land area for each elevational zone (500 $\mathrm{m}$ increments).

densities of endemic species (calculated as the number of endemic species per $1000 \mathrm{~km}^{2}$ land area for each altitudinal zone) against altitude (Figure 6), the differences between the families are much less pronounced. All families show an optimum between 1000 and $3500 \mathrm{~m}$, with the exception of the Poaceae, which have their optimum at $4500 \mathrm{~m}$. This is largely a consequence of the fact that the land areas for the zones of mid-altitude are the smallest (Table 5), and that even a rather small number of endemics in these zones will result in a rather high density of 
Table 3. Ten families with the largest number of endemic species in Peru and Ecuador in order of their ranking in Peru, with the respective ranking for Ecuador given in parentheses.

\begin{tabular}{lllrl}
\hline Family name & Peru & Percentage & Ecuador & Percentage \\
\hline Asteraceae & 729 & 50.9 & $370(2)$ & 42.9 \\
Piperaceae & 528 & 65.1 & $134(6)$ & 30.6 \\
Orchidaceae & 369 & 23.3 & $1303(1)$ & 40.2 \\
Fabaceae & 280 & 28.8 & $61(14)$ & 11.4 \\
Bromeliaceae & 239 & 56.9 & $151(5)$ & 34.3 \\
Melastomataceae & 230 & 36.1 & $199(3)$ & 36 \\
Cactaceae & 186 & 75.3 & $19(31)$ & 40.4 \\
Rubiaceae & 165 & 28.5 & $100(8)$ & 20.3 \\
Solanaceae & 162 & 30.1 & $78(10)$ & 23.1 \\
Poaceae & 112 & 15.6 & $65(13)$ & 14.4 \\
\hline
\end{tabular}

endemics. The altitudinal distribution of endemic species of the entire flora (Figure 1A) differs markedly from the altitudinal distribution of endemics of individual families (Figure 5); only Fabaceae and Melastomataceae approach the pattern of the entire flora reasonably close. The differences between the patterns of density of endemics of individual families (Figure 6) and of the total flora (Figure 1B) are less striking; with the exception of the Poaceae all have their greatest density of endemics at mid-altitude. Among the top 10 families in Peru the percentages of endemic species vary greatly, from $15.6 \%$ in the Poaceae to $65.1 \%$ in the Piperaceae; this variation is less in Ecuador, but still significant (11.4\% in the Fabaceae to $42.9 \%$ in the Asteraceae) (Table 3).

\section{Discussion and recommendations}

This paper presents the first detailed study of the elevational distribution of endemic species of Peru based on an entire flora. Analyses of vegetation or studies of floristic composition typically include all species in a given area and not just endemic species, mainly because during the fieldwork phase of such studies the identities of the species (and whether they are endemic or not) are not yet known. All recent detailed field studies (for instance, Mori et al. 1997; Vasquez Martinez 1997; Ribeiro et al. 1999) have yielded undescribed species; the same applies to studies aimed at particular plant groups. Smith et al. (1999) reported 145 species of Pteridophytes as new for the Flora of Bolivia based almost exclusively on fieldwork by $M$. Kessler and estimated that the number of undescribed species approached the number of new records. Major (1988) mentioned the lack of information on endemics in tropical countries; others (Jørgensen and León-Yánez 1999) pointed to the richness of endemics in the Andean region but did not go into further details. Balslev (1988) found that in Ecuador the percentages of endemics at mid-elevation $(900-3000 \mathrm{~m})$ and high elevation (above $3000 \mathrm{~m}$ ) were much higher than in the 
lowlands (below $900 \mathrm{~m}$ ). However, his sample was small, 536 species of which 160 species were endemic, and was taken from revisions available to him. His findings are difficult to compare with ours, partly because his elevational zones are so different from the ones we use in our study. Also, the number of endemic species included in his study was much smaller than the number of endemics in the present study (160 versus 5323 species). Only one other study to date has analyzed the elevational patterns of endemism for an entire flora at both the country and family level (Kessler 2002b). However, because Kessler expressed endemism as the percentage of endemic species among a particular family or genus with the highest value rescaled at $100 \%$, and we look at the absolute number of endemic species in a group, our conclusions are difficult to compare with Kessler's. We did not use the rescaling as accepted by Kessler because it gives no information about the numbers of endemic species and suggests maxima in endemism at altitudes where very few endemic species occur.

Our study shows that endemic species are not evenly distributed over Peru, and that the greatest density and highest absolute number of endemic species are found along the Andean slopes between 2500 and $3000 \mathrm{~m}$ (Figure 1). Looking at the elevational distribution for the density of endemics grouped by life form, we conclude that while peaks vary, all life forms show increasing density of endemism with elevation, dropping off above the timberline (Figure 4). Even when analyzed for absolute number of endemics, herbs, shrubs, and epiphytes still show maxima in the numbers of endemic species between 1500-3000 m (Figure 3). For the six life forms in this study the highest percentage of endemism occurs in herbs, shrubs, and epiphytes (Table 4). Among the 10 families with the highest number of endemics, density of endemics peaks at mid- to high elevations (1500-4500 m), yet there is much disparity between families in their altitudinal distribution of endemism (calculated with both absolute numbers and density) (Figures 5 and 6).

Much of the research on plant communities, species richness, and species conservation is based on studies that measure woody plants $\geq 2.5 \mathrm{~cm}$ diameter at breast height (Pitman et al. 1999; Phillips and Miller 2002). Obviously, such research is very useful, but the fact that most species of vascular plants are not included places a limit on the conclusions one can draw from it. When we look only at endemic trees, we may conclude that the highest number of endemics is found in the lowlands, but when we consider all endemic species, we find that this conclusion is not supported. Adding herbs, shrubs, and epiphytes to forest inventories, plot studies, and such will require a great deal more effort in collecting and especially in identification; but because most species in tropical forests are herbs, shrubs, and epiphytes, the exclusion of these life forms from vegetation studies seems hardly justified. Only one study dealing with species numbers of shrubs, herbs, epiphytes, and lianas (non-trees) has been published (Gentry and Dodson 1987), and we strongly support Gentry and Dodson's recommendation to include non-trees in inventory studies. Our results indicate that herbs, shrubs, and epiphytes not only contain a higher percentage of endemics (number of endemic species to total species within life form) than do trees, but also have their peaks of endemism (both absolute number and density) in the mid-elevation (2000-3500 m) range of the 
Table 4. Percentage of endemic species for each of six life forms. Total number of endemic species and total species overall differ from absolute number of endemic and non-endemic species used from the Catalogue in this study because some endemic species occur in more than one life form.

\begin{tabular}{lcccccrr}
\hline & Herbs & Shrubs & Trees & Epiphytes & Lianas & Vines & Total \\
\hline Endemics & 2139 & 1965 & 700 & 300 & 195 & 230 & 5529 \\
All species & 5861 & 5008 & 3478 & 1097 & 1076 & 1061 & 17581 \\
Percentage & 36.50 & 39.24 & 20.13 & 27.35 & 18.12 & 21.68 & 31.45 \\
\hline
\end{tabular}

Table 5. Elevational distribution of protected areas within Peru. The percent of protected areas within each altitudinal zone was calculated based on protected areas data obtained from INRENA.

\begin{tabular}{cccc}
\hline Elevation $(\mathrm{m})$ & Protected $\left(\mathrm{km}^{2}\right)$ & Area $\left(\mathrm{km}^{2}\right)$ & \% Protected \\
\hline $0-500$ & 87614 & 649720 & 13.5 \\
$500-1000$ & 41268 & 138027 & 29.9 \\
$1000-1500$ & 11034 & 60059 & 18.4 \\
$1500-2000$ & 4998 & 49308 & 10.1 \\
$2000-2500$ & 3806 & 46331 & 8.2 \\
$2500-3000$ & 2797 & 45672 & 6.1 \\
$3000-3500$ & 2451 & 49463 & 5.0 \\
$3500-4000$ & 4675 & 91131 & 5.1 \\
$4000-4500$ & 6424 & 91163 & 7.0 \\
$4500-5000$ & 4530 & 66740 & 6.8 \\
\hline
\end{tabular}

Andes. These findings should be taken into consideration when planning reserves aimed at the conservation and protection of plant species.

Less than $10 \%$ of the land area for each of the montane zones $(2000-4500 \mathrm{~m})$ where the highest density of endemics occurs is protected, compared to 13.5-29.9\% in the lower elevations $(0-1000 \mathrm{~m})$ (Table 5; Figure 1). Clearly, the zones with the highest density of endemic species are greatly underrepresented in the protected areas. When considering the conservation of endemic plant species, decision makers should place a greater emphasis on establishing protected areas along the Andean slopes than on enlarging protected areas in the Amazon lowlands. It is not likely that large protected areas can be established on the Andean slopes, because this region is relatively densely populated and because much of the primary vegetation has been destroyed. Still, we believe that a series of smaller protected areas will offer protection for a large proportion of the endemic plant species of the region. We also recommend that protection efforts be aimed at the conservation of areas with undisturbed vegetation and not at the protection of individual species; the large number of endemic species and our poor knowledge of the distribution of plants in Peru makes this last approach not feasible. Finally, we recommend that a greater effort be made towards fieldwork and collecting on the Andean slopes as well as a greater effort to study collections from this area. 


\section{Acknowledgements}

We thank P. Jørgensen for making the spreadsheet with data of the Peru Catalogue available. Comments from Olga Martha Montiel, Doug Stevens and Gail Milder, Michael Kessler and an anonymous reviewer improved the manuscript. ArcView software was generously donated by Environmental Systems Research Institute (ESRI).

\section{References}

Balslev H. 1988. Distribution patterns of Ecuadorean plant species. Taxon 37: 567-577.

Brako L. and Zarucchi J.L. (eds) 1993. Catalogue of the Flowering Plants and Gymnosperms of Peru. Missouri Botanical Garden, St. Louis, Missouri.

Brooks T.M., Mittermeier R.A., Mittermeier C.G., da Fonseca G.A.B., Rylands A.B., Konstant W.R. et al. 2002. Habitat loss and extinction in the hotspots of biodiversity. Conservation Biology 16: 909-923.

ESRI 1999. Data and Maps 1:1000000. Environmental Systems Research Institute, Inc., Redlands, California.

Gentry A.H. 1986. Endemism in tropical versus temperate communities. In: Soulé M.E. (ed) Conservation Biology: The Science of Scarcity and Diversity. Sinauer Associates, Sunderland, Massachusetts, pp. 153-181.

Gentry A.H. 1995. Patterns of diversity and floristic composition in neotropical montane forests. In: Churchill S.P., Balslev H., Forero E. and Luteyn J.L. (eds), Biodiversity and Conservation of Neotropical Montane Forests. New York Botanical Gardens, Bronx, New York, pp. 103-126.

Gentry A.H. and Dodson C.H. 1987. Contribution of non-trees to species richness of a tropical rain forest. Biotropica 19: 149-156.

Ibisch P.L., Boegner A., Nieder J. and Barthlott W. 1996. How diverse are neotropical epiphytes? An analysis based on the 'Catalogue of the Flowering Plants and Gymnosperms of Peru'. Ecotropica 2: 13-28.

Jørgensen P.M. and Léon-Yánez S. (eds) 1999. Catalogue of the Vascular Plants of Ecuador. Missouri Botanical Garden Press, St. Louis, Missouri.

Kessler M. 2000. Elevational gradients in species richness and endemism of selected plant groups in the central Bolivian Andes. Plant Ecology 149: 181-193.

Kessler M. 2001a. Patterns of diversity and range size of selected plant groups along an elevational transect in the Bolivian Andes. Biodiversity and Conservation 10: 1897-1921.

Kessler M. 2001b. Maximum plant-community endemism at intermediate intensities of anthropogenic disturbance in Bolivian montane forests. Conservation Biology 15: 634-641.

Kessler M. 2002a. Environmental patterns and ecological correlates of range size among bromeliad communities of Andean forests in Bolivia. The Botanical Review 68: 100-127.

Kessler M. 2002b. The elevational gradient of Andean plant endemism: varying influences of taxonspecific traits and topography at different taxonomic levels. Journal of Biogeography 29: 1159-1165.

Kessler M., Herzog S.K., Fjeldsa J. and Bach K. 2001. Species richness and endemism of plant and bird communities along two gradients of elevation, humidity and land use in the Bolivian Andes. Diversity and Distributions 7: 61-77.

Knapp S. 2002. Assessing patterns of plant endemism in Neotropical Uplands. The Botanical Review 68: 22-37.

Kruckeberg A.R. and Rabinowitz D. 1985. Biological aspects of endemism in higher plants. Annual Review of Ecology Systematics 16: 447-479.

Luteyn J.L. 2002. Diversity, adaptation, and endemism in Neotropical Ericaceae: biogeographical patterns in the Vaccinieae. The Botanical Review 68: 55-87.

Major J. 1988. Endemism: a botanical perspective. In: Myers A.A. and Giller P.S. (eds) Analytical Biogeography, An Integrated Approach to the Study of Animal and Plant Distributions. Chapman \& Hall, London. 
Myers N., Mittermeier R.A., Mittermeier C.G., de Fonseca G.A.B. and Kent J. 2000. Biodiversity and hotspots for conservation priorities. Nature 403: 853-858.

Mittermeier R.A., Myers N., Thomsen J.B., da Fonseca G.A.B. and Olivieri S. 1998. Biodiversity hotspots and major tropical wilderness areas: approaches to setting conservation priorities. Conservation Biology 12: 516-520.

Mori S., Cremers G., Gracie C., de Granville J. and Mitchell J.D. 1997. Guide to the Vascular Plants of Central French Guiana. Memoirs of the New York Botanical Gardens 76.

Phillips O. and Miller J.S. 2002. Global Patterns of Plant Diversity: Alwyn H. Gentry's Forest Transect Data Set. Missouri Botanical Garden Press, St. Louis, Missouri.

Pitman N.C., Terborgh J., Silman M.R. and P. Nunez V. 1999. Tree species distributions in an upper Amazonian forest. Ecology 80: 2651-2661.

Ribeiro J.E., Hopkins M.J.G., Vicentini A., Sothers C.A., Costa M.A., Brito J.M. et al. 1999. Flora da Reserva Ducke. INPA-DFID, Manaus, Brazil.

Sklenar P. and Jørgensen P.M. 1999. Distribution patterns of paramo plants in Ecuador. Journal of Biogeography 26: 681-691.

Smith A.R., Kessler M. and Gonzales J. 1999. New records of Pteridophytes from Bolivia. American Fern Journal 89: 244-266.

Valencia R., Pitman N., León-Yánez S. and Jørgensen P.M. 2000. Libro rojo de las plantas endemicas del Ecuador. Herbario QCA, Pontificia Universidad Catolica del Ecuador, Quito, Ecuador.

Vasquez Martinez R. 1997. Florula de las Reservas Biologicas de Iquitos, Peru. Monographs in Systematic Botany Missouri Botanical Gardens 63.

U.S. Geological Survey 1996. Global 30-Arc-Second Elevation Data Set. U.S. Geological Survey, Sioux Falls, South Dakota.

Young K.R., Ulloa Ulloa C., Luteyn J.L. and Knapp S. 2002. Plant evolution and endemism in Andean South America: an introduction. The Botanical Review 68: 4-27.

Zhou G. 2001. Area Calculation for Polygons. http://gis.esri.com/arcscripts/scripts.cfm. 